\title{
SYNTHESIS, CHARACTERIZATION AND ANTIOXIDANT ACTIVITY OF SILVER NANOPARTICLES STABILIZED BY AQUEOUS EXTRACTS OF WILD BLACKBERRY (Rubus spp.) AND RASPBERRY (Rubus idaeus L.) LEAVES
}

Marija S. Stevanović ${ }^{*}$, Jelena B. Zvezdanović², Ljiljana P. Stanojevićc, Jelena S. Stanojević2 , Sanja M. Petrović ${ }^{2}$, Milorad D. Cakić ${ }^{2}$, Dragan J. Cvetković

\footnotetext{
${ }^{1}$ Scholar of the Ministry of Education, Science and Technological Development of the Republic of Serbia, Faculty of Technology, University of Niš, Leskovac, Serbia

2University of Niš, Faculty of Technology, Leskovac, Serbia
}

The green methods of silver nanoparticles (AgNPs) synthesis and their stabilization by biomolecules from aqueous extracts of wild blackberry (Rubus spp.) and raspberry (Rubus idaeus L.) leaves are described. The extracts, obtained from both plants by maceration and reflux extraction were used in nanoparticles synthesis at two different temperatures (room and boiling). Structural characterization of silver nanoparticles synthesized from obtained extracts (AgNPs-E) was performed by UVVis and FTIR spectroscopy. The size and high stability of synthesized nanoparticles at room temperature in the dark were proven by the position and monitoring of the surface plasmon resonance (SPR) band in the UV-Vis spectra. A chemical composition of pure extracts and supernatants, obtained by centrifugation of AgNPs-E suspensions, was investigated by LC-MS analysis. Most of the identified compounds belong to phenolic acids and flavonoids derivatives. A comparative LC-MS analysis of the extracts and AgNPs-E supernatants showed that some compounds from the extracts were involved in a higher extent in $\mathrm{Ag}^{+}$ions reduction and formed particles stabilization, suggesting the existence of a structure-activity relationship. The synthesized AgNPs-E showed a comparatively high antioxidant activity estimated by the DPPH test suggesting that they should be taken into account in a further design of skin-protective preparations.
(ORIGINAL SCIENTIFIC PAPER) UDC 582.712:66.063.4:546.57

Keywords: blackberry, raspberry, aqueous extract, silver nanoparticles, antioxidant activity

\section{Introduction}

Nanoparticles can be defined as particles formed from a reduced chemical element with dimensions in the range of $1-100 \mathrm{~nm}$. Formed nanoparticles retain the properties of the element and usually acquire some other significant characteristics. Based on their specific features, nanoparticles have a great application in many areas (diagnostics, therapy, drugs, etc.). The binding of a reducing molecule to particles surface results in a change of the nanoparticles suspension color [1]. Due to their unique properties (electrical, optical and biological), silver nanoparticles (AgNPs) have been widely used in medicine, catalysis, and drug delivery. After being found to have a strong antimicrobial activity, these particles were used in clothing, cosmetic products and food industry. Some studies reviewed that AgNPs interact with HIV-1 virus inhibiting the binding to the host cell in vitro [1].

Plant extracts contain molecules that play a role of reducing and capping agents in the formed AgNPs. The usage of plants extracts in these purposes is considered as a green synthetic method representing a modern procedure with constantly growing interest. Phytochemicals with different functional groups (flavones, ketones, terpenoids, aldehydes, amides, carboxylic acids, proteins, glycosides etc.) reduce $\mathrm{Ag}^{+}$to $\mathrm{Ag}^{0}$ stabilizing the formed AgNPs [2]. In this work, the leaves of two wild grown plants, blackberry and raspberry, have been used as a source of phytochemicals in the form of aqueous extracts obtained at two extraction temperatures (room and boiling).

Blackberry (Rubus sp.) belongs to perennial deciduous plants, with a significant content of phenolic compounds (anthocyanins, flavonols, chlorogenic acid and procyanidines) that exhibit an important effect on human health, classified as dietary antioxidants due to their biological activity [3]. Anthocyanins, catechins and flavonols are molecules that can effectively prevent the onset of diseases such as cardiovascular diseases and type II diabetes. They also have a relevant role in the defense of plants against biotic and abiotic stresses. Flavonols, as a class of flavonoids, are located in green parts of the plants protecting them from the reactive oxygen species generated by abiotic stress (e.g. UV-B radiation and soil saturation), as well as a biotic stress as a pathogen challenge. Another important

\footnotetext{
*Author address: Marija Stevanović, University of Niš, Faculty of Technology,

Bulevar Oslobođenja 124, 16000 Leskovac, Serbia

E-mail: marijast190@gmail.com

The manuscript received: May, 17, 2019.

Paper accepted: June, 16, 2019.
} 
role is plant growth regulation [4].

Raspberry (Rubus idaeus L.) is a perennial, deciduous plant, a member of the Rosaceae family successfully growing in areas with mild winter and long moderate summer. Raspberry is rich in very important compounds, such as aromatic hydrocarbons, alcohols, ketones, aldehydes, monoterpenes, C13 - norisoprenoids etc. [5].

Based on our literature research, there is no data about the synthesis and activity of silver nanoparticles stabilized by extracts (AgNPs-E) from wild blackberry and raspberry leaves. According to this knowledge, the synthesis, characterization and antioxidant activity of AgNPs-E synthesized by the above-mentioned extracts are described in the presented work.

\section{Experimental}

\section{Materials}

Reagents and Chemicals

All reagents were of the analytical grade used without further purification. Silver nitrate $\left(\mathrm{AgNO}_{3}\right)$, used as a silver precursor was obtained from RTB Bor Grupa, Serbia; DPPH (2,2-diphenyl-1-picrylhydrazyl) radical from SigmaAldrich Corporation. All aqueous solutions and extracts were prepared with redistilled water.

\section{Plant material}

Wild blackberry and raspberry leaves were collected from the plants grown in Plana village near Crna Trava, Serbia (Latitude $22^{\circ} 19^{\prime} 48.39^{\prime \prime}$, Longitude $42^{\circ} 49^{\prime} 28.45^{\prime \prime}$ and Altitude $1550 \mathrm{~m}$ ) at the beginning of August 2017, after the flowering period. The plant material was dried in the shade at constant air flow, ground and homogenized in an electric mill (laboratory electric mill "BRAUN AROMATIC KSM2") just before use.

\section{Extraction procedure}

Aqueous extracts were obtained by maceration at room temperature, and reflux extraction at boiling temperature with hydromodulus $1: 20 \mathrm{~m} / \mathrm{v}$ for $120 \mathrm{~min}$. The concentrations of extracts were determined by solvent evaporation from $2 \mathrm{ml}$ aliquots to a constant mass at $105^{\circ} \mathrm{C}$.

\section{Maceration}

Two grams of air-dried plant material (blackberry and raspberry) were macerated with $40 \mathrm{ml}$ of water for 120 minutes at room temperature $(1: 20 \mathrm{~m} / \mathrm{v})$. The extract was separated from the plant material by vacuum filtration on Büchner's funnel after extraction. The obtained extracts were kept in the dark at $-20^{\circ} \mathrm{C}$.

The extracts concentrations, calculated per $100 \mathrm{~g}$ of the air-dried plant material, were determined as $21.7 \mathrm{~g} / 100 \mathrm{~g}$ and $17.6 \mathrm{~g} / 100 \mathrm{~g}$ for blackberry and raspberry extracts, respectively.

\section{Reflux extraction}

Ten grams of the air-dried plant material (blackberry and raspberry) were extracted with $200 \mathrm{ml}$ of water by re- flux extraction at boiling temperature for 120 minutes. The obtained extract was treated by the same procedure described above.

The concentrations of the extracts were determined as $30 \mathrm{~g} / 100 \mathrm{~g}$ and $27.5 \mathrm{~g} / 100 \mathrm{~g}$ for blackberry and raspberry extracts, respectively.

\section{Synthesis of AgNPs-E}

Synthesis of AgNPs using the aqueous blackberry extract (AgNPs-B) was performed by mixing of the extracts obtained by maceration and reflux extraction with $250 \mathrm{ml}$ of the aqueous $\mathrm{AgNO}_{3}$ solution $(0.001 \mathrm{M})$ to the final molar ratio 1:1 (average molar mass of extracts $\sim 460 \mathrm{~g} / \mathrm{mol}$ ). The AgNPs synthesis was performed at room (RT) and boiling (BT) temperature (reflux). The same aliquots of the reaction mixtures were taken during synthesis, 20 times diluted and the UV-Vis spectra were measured.

The synthesis of AgNPs using the raspberry extract (AgNPs-R) was done in the same way described above for the blackberry extract.

The suspensions of all synthesized nanoparticles were subjected to dialysis in order to remove nitrates. Dialysis experiments were carried out in dialysis bags (Spectra/Por Biotech; cellulose ester; MWCO 100000) filled with $20 \mathrm{ml}$ of silver nanoparticles suspension and immersed in $500 \mathrm{ml}$ of re-distilled water at room temperature. The re-distilled water was daily changed up to vanishing of the nitrate peak in the UV-VIS spectra of AgNPs suspensions.

The concentrations of all synthesized AgNPs-E were determined by completing solvent evaporation from $2 \mathrm{ml}$ of aliquots to a constant mass at $105^{\circ} \mathrm{C}$.

\section{Spectroscopic methods}

Spectroscopic characterization of synthesized AgNPs-E, stabilized by blackberry and raspberry leaves extracts, was performed by UV-Vis and FT-IR spectroscopy.

\section{UV-Vis spectroscopy}

The UV-Vis spectra were measured on a spectrophotometer Varian Cary-100 Conc. UV-Vis spectrophotometer in the range of 200-800 nm; computer processing of the recorded UV-VIS spectra was performed by Cary UV-Conc software (Copyrightc, Varian 1999) integrated by using Windows XP OS platform.

\section{Fourier-transform infrared (FTIR) spectroscopy}

Plant extracts and AgNPs-E suspensions were dried at $50{ }^{\circ} \mathrm{C}$ in a vacuum-dryer and mixed with $\mathrm{KBr}$ in the concentration of $1 \%$ for pastilles preparation. The FTIR spectra were measured using BOMEM MB-100 (Hartmann \& Braun, Canada) spectrometer coupled with standard deuterated triglycine sulfate/ $\mathrm{KBr}$ detector with the resolution of $2 \mathrm{~cm}^{-1}$ in $4000-400 \mathrm{~cm}^{-1}$ range. The Win-Bomem Easy TM 3.01 C Level II software (Copyrightc 1991-1994, Galactic Industries Corporation under Windows XP OS platform) was used for spectra processing. 


\section{LC-MS chromatography}

Thermo Scientific liquid chromatography system (UHPLC) coupled with LCQ Fleet Ion Trap Mass Spectrometer (Thermo Fisher Scientific, San Jose, California, USA), equipped with ElectroSpray lonization (ESI), was used for LC-MS analysis. The extracts and the supernatants obtained by centrifugation of AgNPs-E suspensions (10 min at $13500 \mathrm{rpm}$, room $T$ ) have been subjected to LC-MS analysis to predict which kind of compounds mostly takes part in $\mathrm{Ag}^{+}$reduction and AgNPs-E stabilization.

The instrument was controlled and the data analyzed by Xcalibur (version 2.2 SP1.48) and LCQ (version 2.7.0.1103 SP1) software. Hypersil gold C18 column $(50 \times 2.1 \mathrm{~mm}$, $1.9 \mu \mathrm{m}$, Thermo Fisher Scientific) and $0.1 \%$ formic acid in water (A) and $0.1 \%$ formic acid in methanol (B), as a mobile phase, were used for chromatographic separation. A linear gradient program $(0.250 \mathrm{ml} / \mathrm{min})$ was applied as component B increasing: $10-30 \%$ in $0-2 \mathrm{~min}$, to $35 \%$ in $2-4 \mathrm{~min}$, to $40 \%$ in $4-5 \mathrm{~min}$, to $50 \%$ in $5-8 \mathrm{~min}$, to $80 \%$ in $8-9 \mathrm{~min}$, to $90 \%$ in $9-11 \mathrm{~min}$, held on $90 \%$ in $11-12 \mathrm{~min}$, back to $10 \%$ in 12-12.1 min and held on $10 \%$ in $12.1-20$ min; injection volume of $8 \mu$, column temperature of $25^{\circ} \mathrm{C}$, monitoring wavelengths 230, 280, 360 and $430 \mathrm{~nm}$. The spectrometer operation was performed in a negative mode and ESIsource parameters were: source voltage $4.5 \mathrm{kV}$, capillary voltage $41.00 \mathrm{~V}$; tube lens voltage $95.4 \mathrm{~V}$ and capillary temperature $350{ }^{\circ} \mathrm{C}$; sheath and auxiliary gas flow (N2), 32 and 8 (arbitrary units) and full range acquisition (130-1000 m/z). The normalized collision energy of the CID cell was set at $25 \mathrm{eV}$.

\section{DPPH-test}

One milliliter of DPPH radical solution in the concentration of $3 \times 10^{-4} \mathrm{~mol} / / \mathrm{l}$ was added to $2.5 \mathrm{ml}$ of AgNPs-E solutions in different concentrations $(0.001-0.01 \mathrm{mg} / \mathrm{ml})$. The mixture was incubated for $20 \mathrm{~min}$ at room temperature in the dark followed by absorbance measuring at 517 $\mathrm{nm}$. The absorbance of DPPH radical solution diluted in an adequate proportion $(1.0 \mathrm{ml}$ of DPPH radical solution

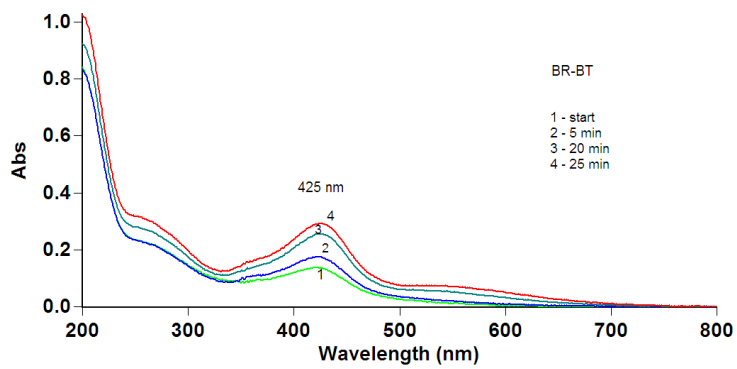

a) diluted with $2.5 \mathrm{ml}$ of ethanol - "control") was also measured, as well as the absorbance of AgNPs-E suspension without DPPH radical added $(2.5 \mathrm{ml}$ of AgNPs-E suspension diluted with $1.0 \mathrm{ml}$ of ethanol - "blank"). DPPH test was performed in the same way for the extracts used in AgNPs-E synthesis in the broader concentration range of $0.001-1 \mathrm{mg} / \mathrm{ml}$. Free radical scavenging activity was calculated according to equation (1) $[6,7]$ :

$D P P H$ radical scavenging activity $(\%)=100-\left[\left(A_{s}-A_{B}\right) \times \frac{100}{A_{c}}\right] \ldots \ldots . .(1)$

The absorbances of the „sample“, blank"and "control"are denoted as $A_{\mathrm{S}}, A_{\mathrm{B}}$ and $A_{\mathrm{C}}$, respectively.

\section{Results and discussion}

UV-Vis characterization of AgNPs-E

Characterization of AgNPs-E synthesized by aqueous extracts of blackberry and raspberry leaves was done by UV-Vis spectroscopy. Actually, the UV-Vis spectroscopy is a very often used method for AgNPs synthesis monitoring, since it is followed by color changes of the reaction mixture and an easily observed surface plasmon resonance (SPR) band at $\sim 420 \mathrm{~nm}$. The increscent band is used for the size and stability determination of formed nanoparticles [8-10]. The changes of UV-Vis spectra during AgNPs-E synthesis at boiling T, using aqueous extracts of blackberry and raspberry leaves, obtained by maceration (M) or reflux extraction $(R)$ were shown in Fig.1. The type of plant extracts, the methods of extraction and synthesis conditions, particularly in terms of the reaction temperature were summarized by abbreviations as follows: BR-BT (Blackberry, Reflux extraction - nanoparticles synthesis at Boiling Temperature), RM-BT (Raspberry, Maceration - nanoparticles synthesis at Boiling Temperature), etc. It should be emphasized that the spectra obtained for all synthesized nanoparticles were similar and the spectra shown in Fig. 1 (for BR-BT and RMBT) were chosen as representative ones.

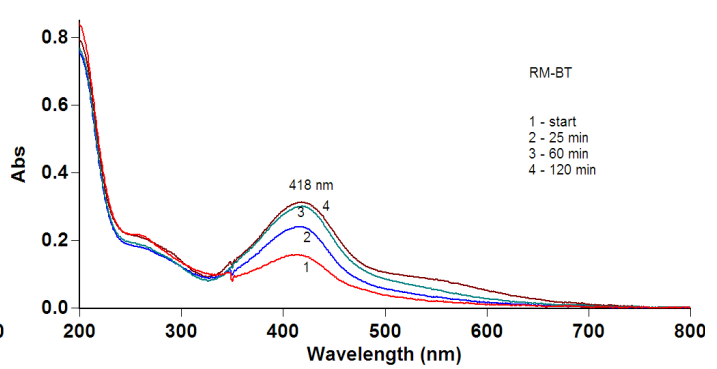

b)

Figure 1. UV-Vis spectra of reaction mixtures measured during AgNPs-E synthesis at boiling $T$ using the aqueous extract of blackberry leaves obtained by reflux extraction (a) and boiling $T$ using the aqueous extract of raspberry leaves obtained by maceration (b).

The formation of the so-called SPR (surface plasmon resonance) band in the range of $380-500 \mathrm{~nm}$ is well-known evidence of AgNPs formation by $\mathrm{Ag}^{+}$ions reduction [8]. The synthesis and stabilization of AgNPs by phytochemicals from plant extracts has been monitored by SPR band in our previous work [2], as well as by other authors [9, 11].
The nitrates are removed from the reaction mixtures by dialysis. UV-Vis spectra of non-dialyzed and dialyzed AgNPs-E suspensions (for BR-BT and RM-BT) are presented in Fig.2. The dialysis process was monitored via a nitrate band at $\sim 270 \mathrm{~nm}$ vanishing. The disappearance of the nitrate band represents clear evidence that nitrates are re- 
moved by dialysis from AgNPs-E suspensions. The UV-Vis spectra of other AgNPs-E suspensions had a very similar configuration to the presented ones. All further experiments are performed with AgNPs-E purified by dialysis in the described manner.

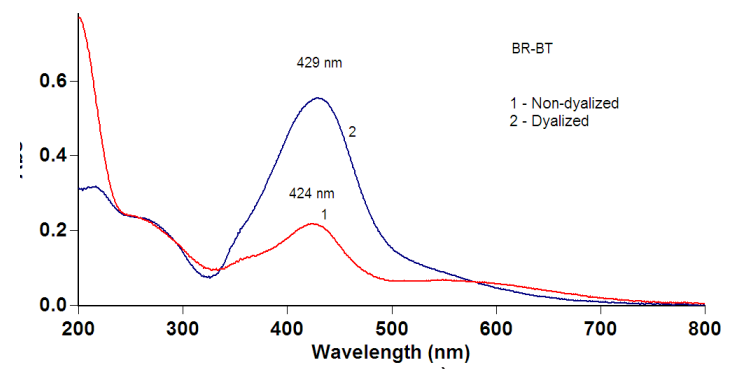

a)

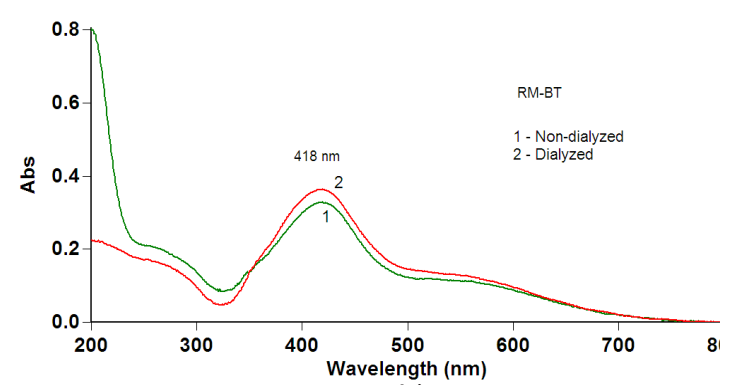

b)

Figure 2. UV-Vis spectra of non-dialyzed and dialyzed AgNPs-E suspensions synthesized at boiling $T$, using the aqueous extract of blackberry leaves obtained by reflux extraction (a) and boiling $T$ using the aqueous extract of raspberry leaves obtained by maceration (b).

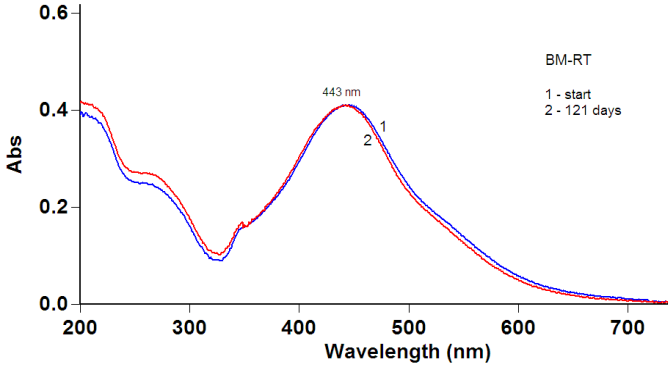

a)

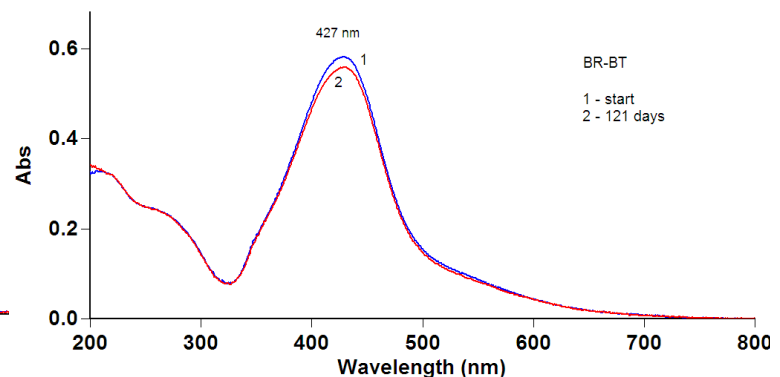

b)

Figure 3. UV-Vis spectra of AgNPs-E synthesized from the blackberry extract at: room $T$, the extract obtained by maceration (a), and boiling $T$, the extract obtained by reflux extraction (b).

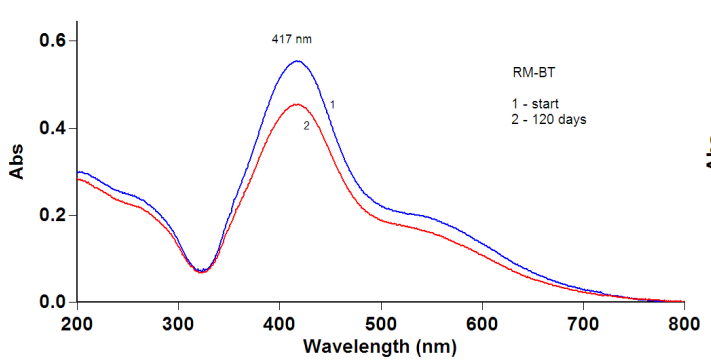

a)

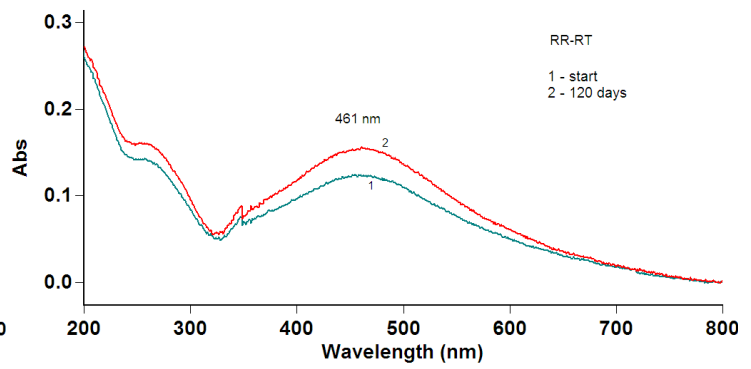

b)

Figure 4. UV-Vis spectra of AgNPs-E synthesized from the raspberry extract at boiling $T$, the extract obtained by maceration (a), and room $T$, the extract obtained by reflux extraction (b).

The size of synthesized AgNPs-E is possible to predict according to the SPR band position, since the band maximum $(400-480 \mathrm{~nm})$ is directly proportional to the particles size $(1-80 \mathrm{~nm})$ [8]. The UV-Vis spectra of AgNPs synthesized at room and boiling $T$ from the blackberry extract obtained by maceration and reflux extraction (BM-RT and BR-BT) are shown in Fig. 3. It can be noticed that the sizes of synthesized nanoparticles significantly differ based on the SPR band position. The maxima of SPR bands for BMRT (Fig. 3a) and BR-BT (Fig.3b) were at $\sim 443$ and $\sim 427 \mathrm{~nm}$, suggesting the particles size of $\sim 43$ and $\sim 27 \mathrm{~nm}$, respectively. The maxima of the SPR band have not been blue/ red shifted during storage at room temperature, in the dark for 121 days, indicating high particles stability and lack of aggregation.

The UV-Vis spectra of AgNPs synthesized at room and boiling $T$ from the raspberry extract obtained by maceration and reflux extraction (RM-BT and RR-RT) are shown in Fig.4. The maxima of SPR bands for RM-BT (Fig.4a) and RR-RT (Fig.4b) were at $\sim 417$ and $\sim 461 \mathrm{~nm}$, suggesting the particles size of $\sim 17$ and $\sim 61 \mathrm{~nm}$, respectively. According to the results obtained (Figs.3\&4) it can be concluded that the synthesis at boiling $T$ produces AgNPs-E smaller in size (27 and $17 \mathrm{~nm}$ for BR-BT and RM-BT, respectively) compared to those synthesized at room temperature (43 and $61 \mathrm{~nm}$ for BM-RT and RR-RT, respectively). Again, the formed AgNPs-E have shown high stability and lack of aggregation since the maxima 
of the SPR bands have not been blue/red shifted during storage at room temperature, in the dark, for 120 days. The configuration of the SPR band is also relevant besides its position (maximum). The AgNPs stabilized by plant extracts were characterized as fine, uniform, spherical, resulting in a relatively narrow and symmetric SPR band [12]. Furthermore, the width and intensity of the SPR band depend on the size and shape of the formed nanoparticles [13]. Higher absorbance and a narrow peak suggest on high uniformity of the formed nanoparticles (Fig. 3b, BR-BT). The band of BM-RT in Fig.3a is broader with a slightly indicated shoulder at longer wavelengths side suggesting lower uniformity of formed nanoparticles and even a non-spherical shape to some extent [14]. The mentioned effects are more noticeable in the RM-BT AgNPs suspension (Fig.4a) while the AgNPs-E in the RR-RT suspension (Fig.4b) were more homogeneous in shape with a broader size distribution. Finally, the UV-Vis spectra presented in Figs.3\&4 confirmed high stability of formed AgNPs-E over a long time period at room $T$ in the dark. It can also be noticed that the blackberry extract (Fig.3) produced more uniformly AgNPs-E with relatively narrow size distribution compared to the raspberry extract (Fig.4).

\section{FTIR spectroscopy}

The FTIR spectra of AgNPs-E synthesized from blackberry and raspberry extracts, as well as the spectra of pure extracts are presented in Figs.5\&6, respectively. Dialyzed AgNPs-E suspensions are used in order to avoid a high concentration of free nitrates in the systems. FTIR spectra of the blackberry extract obtained by maceration and AgNPs-E, synthesized at room $T$ using this extract are shown in Fig.5.

FTIR spectra of the raspberry extract obtained by reflux extraction and AgNPs-E, synthesized at boiling $T$ using this extract, are shown in Fig.6.

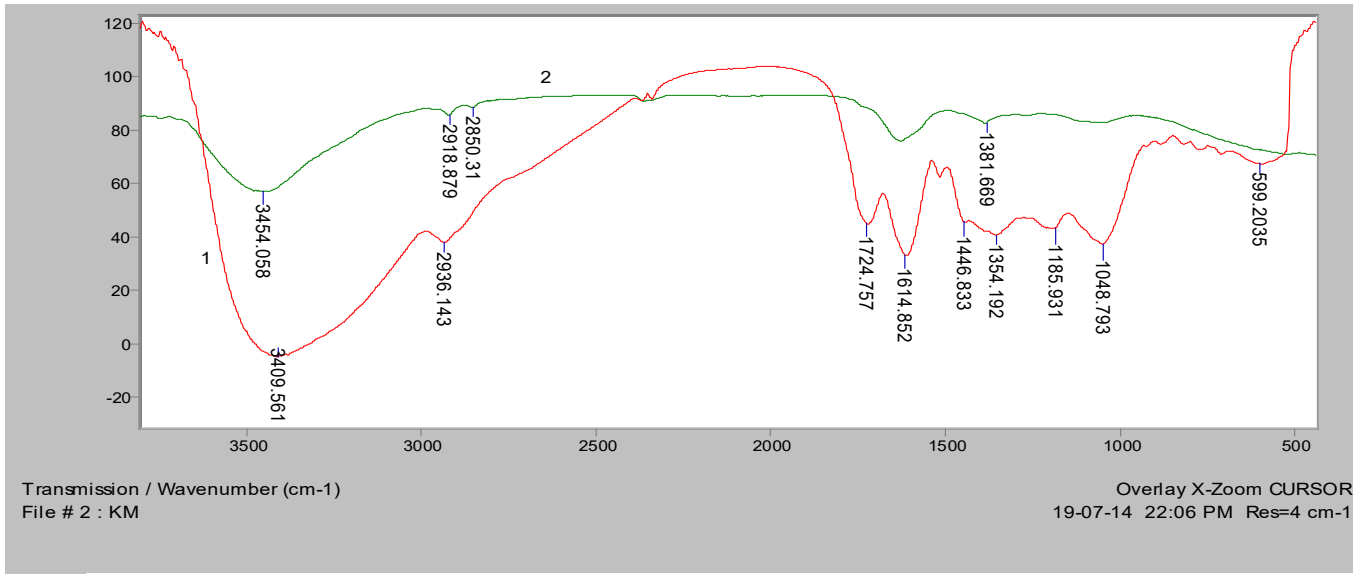

Figure 5. FTIR spectra of the blackberry extract obtained by maceration (1) and AgNPs-E synthesized at room $T(2)$.

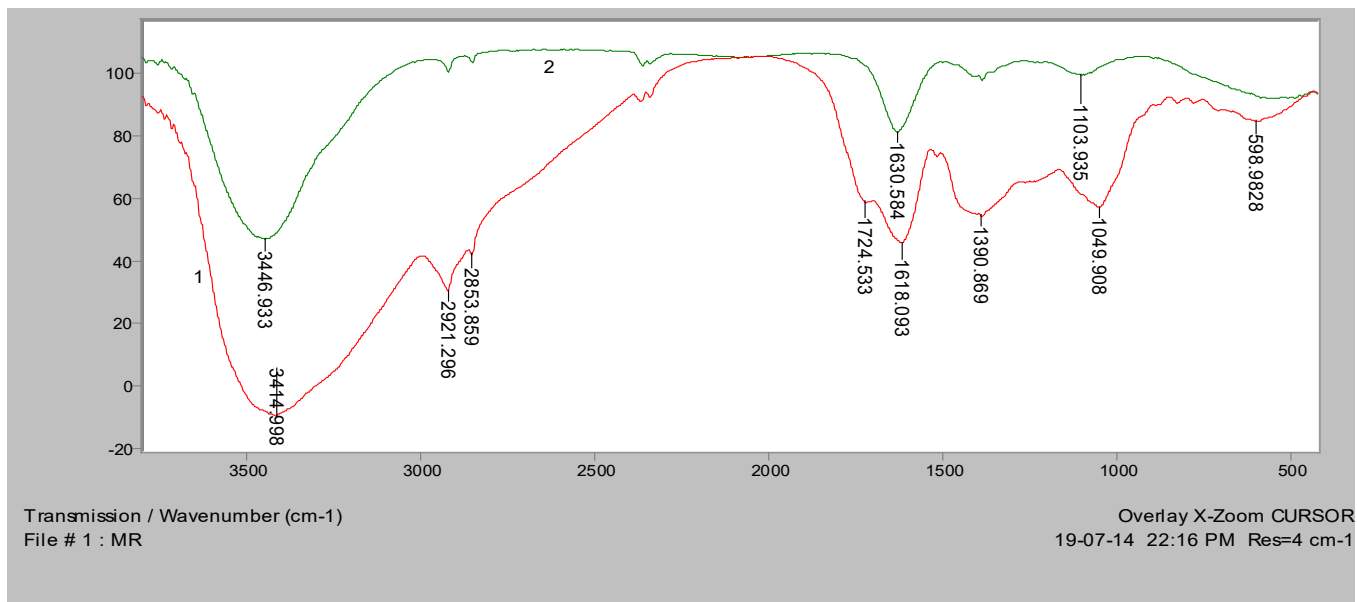

Figure 6. FTIR spectra of the raspberry extract obtained by reflux extraction (1) and AgNPs-E synthesized at boiling $T(2)$.

The functional groups of biomolecules engaged in silver ions reduction participate in agglomeration preventing and stabilization enhancing at the same time, and they can be indicated by spectral structural correlation
$[2,15,16]$. FTIR spectra of the selected extracts and synthesized AgNPs-E (BM-RT and RR-BT) are shown in Figs. $5 \& 6$ as an illustration used for the prediction of the functional groups involved in $\mathrm{Ag}^{+}$ions reduction 
end nanoparticles stabilization. A number of bands can be observed in the spectra of the extracts noticing that the blackberry extract (Fig.5) possesses more defined bands compared to the raspberry extract (Fig.6). A relatively large number of wide complex bands indicate a very complex structure of the extracts. The bands in $3600-3200 \mathrm{~cm}^{-1}$ region originate from $\mathrm{v}-\mathrm{OH}$ vibrations (alcohols, phenols, carboxylic acids) and/or $v-\mathrm{NH}$ vibrations (amines, amides, peptides and proteins). Valent vibrations of $\mathrm{CH}_{2}$ groups $(\mathrm{VCH})$ are assigned at $2936 \mathrm{~cm}^{-1}$ (Fig.5) and 2921/2853 $\mathrm{cm}^{-1}$ (Fig.6); bands at 1724 and $1614 \mathrm{~cm}^{-1}$ (Fig.5) and 1724 and $1618 \mathrm{~cm}^{-1}$ (Fig.6) can be assigned as $(\mathrm{NH}) \mathrm{C}=\mathrm{O}$ and $\delta \mathrm{N}-\mathrm{H})$, respectively, and/or $v C=O$ and $v C=C$ of polyphenols and organic acids. Wide bands with the maxima around $1354 \mathrm{~cm}-1$ (Fig.5) and $1390 \mathrm{~cm}^{-1}$ (Fig.6), with a shoulder at the higher-frequency side, probably come from alcoholic vibrations $(\delta \mathrm{cH}$ and/or $\delta \mathrm{OH}$ ). Since the presence of polyphenols, organic acids, glycosides, alcohols etc. has been proven by LCMS analysis (see below), the bands in 1200-1000 $\mathrm{cm}^{-1}$ region probably originate from $V C-\mathrm{O}, V C-\mathrm{O}-\mathrm{C}$ and $V C-\mathrm{N}$ vibrations $[2,11,17,18]$.

The spectra of synthesized AgNPs-E (Figs. 5\&6) significantly differ from the spectra of the extracts in terms of the evident intensity decrease or complete disappearance of comparable bands. The intensity of all mentioned bands was decreased after the reduction of silver ions. The bands at $\sim 1724 \mathrm{~cm}^{-1}$ vanished, while the bands $1615 \mathrm{~cm}^{-1}$ are decreased and shifted to a higher wavenumber $\left(\sim 1630 \mathrm{~cm}^{-1}\right)$ (Fig.6). The bands at $\sim 1390 \mathrm{~cm}^{-1}$, as well as the bands in $1200-1000 \mathrm{~cm}^{-1}$ region are significantly decreased and shifted in the AgNPs-E spectra. The obtained results confirm that the reduction of $\mathrm{Ag}^{+}$ions was followed by bonding of ions and extracts molecules during nanoparticles formation [18-21]. The intensity of the bands in $1200-1000 \mathrm{~cm}^{-1}$ region was significantly reduced suggesting that molecules containing functional groups with oxygen or nitrogen such as $\mathrm{NH},(\mathrm{NH}) \mathrm{C}=\mathrm{O}$, $\mathrm{CNO}, \mathrm{C}-\mathrm{O}-\mathrm{C}$ and $\mathrm{OH}$ group, play a certain role in the AgNPs-E stabilization and $\mathrm{Ag}^{+}$ions reduction. The compounds containing mentioned functional groups could be polyphenolics, flavonoids, triterpenoids, proteins, organic acids and polysaccharides [20].

\section{LC-MS analysis}

In order to predict which kind of present compounds mostly takes part in $\mathrm{Ag}^{+}$reduction and AgNPs-E stabilization, the extracts and the supernatants obtained after AgNPs-E centrifugation have been subjected to LC-MS analysis. The chromatogram of the raspberry extract obtained by reflux extraction along with the chromatograms of AgNPs-R supernatants is presented in Fig.7.

The chromatogram of the blackberry extract obtained by reflux extraction along with the chromatograms of AgNPs-B supernatants is presented in Fig.8.

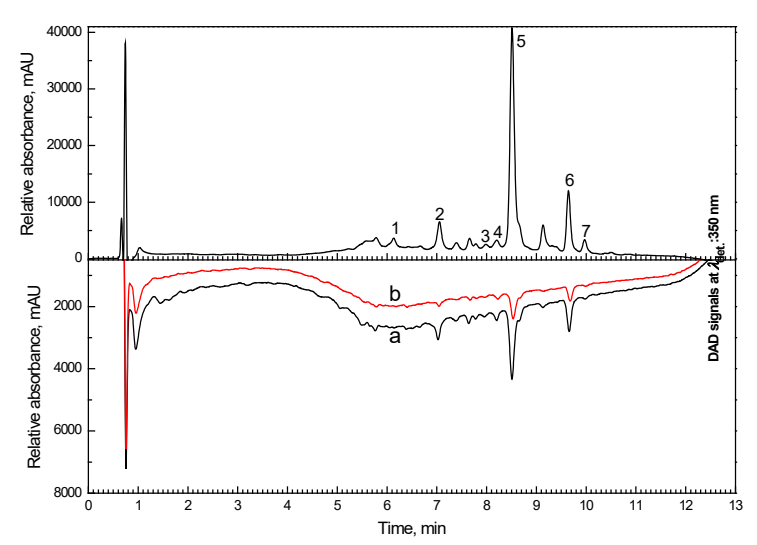

Figure 7. LC-MS chromatogram of the aqueous raspberry extract obtained by reflux extraction (upper part). The chromatograms of AgNPs-R supernatants synthesized at room (a) and boiling (b) $T$ (lower part). The identified compounds are numbered in chromatograms.

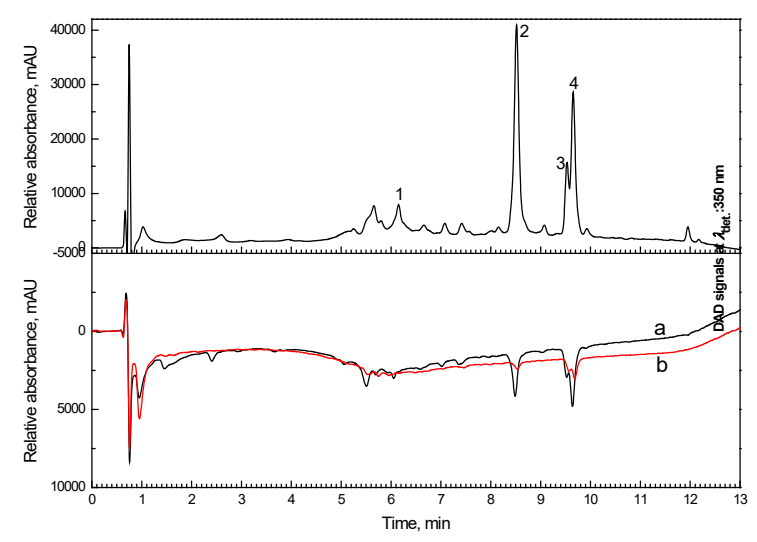

Figure 8. LC-MS chromatogram of the aqueous blackberry extract obtained by reflux extraction (upper part). The chromatograms of AgNPs-B supernatants synthesized at room (a) and boiling (b) $T$ (lower part). The identified compounds are numbered in chromatograms.

A list of some compounds, proven to be more active in AgNPs-E stabilization and identified from the LC-MS chromatograms, is given in Table 1. The fractions of the peak area of each identified compound in total peaks area (of all identified compounds) were calculated in order to predict a possible difference in the biomolecules ability to AgNPs-E stabilization and $\mathrm{Ag}^{+}$ions reduction. The fractions were calculated using absolute values of peaks areas obtained from the chromatograms by an adequate software package. According to calculated fractions, it can be concluded that ratio of analyzed compounds has been changed during AgNPs-E synthesis, i.e. the fractions in the extracts significantly differ from those in supernatants, which is especially noticeable for the raspberry extract (Table 1). The differences in calculated area fractions suggest there is a difference in abil- 
ity (reactivity) of the compounds of extracts to $\mathrm{Ag}^{+}$ions reduction, although the identified compounds mostly belong to the phenolic group of molecules.
The most represented compounds in raspberry extracts (Fig.7) were identified as quercetin glucuronide (no.5) and kaempferol-3-glucuronide (no.6) (Table 1).

Table 1. The list of compounds identified in aqueous extracts of raspberry and blackberry leaves (obtained by reflux extraction) by LC-MS analysis.

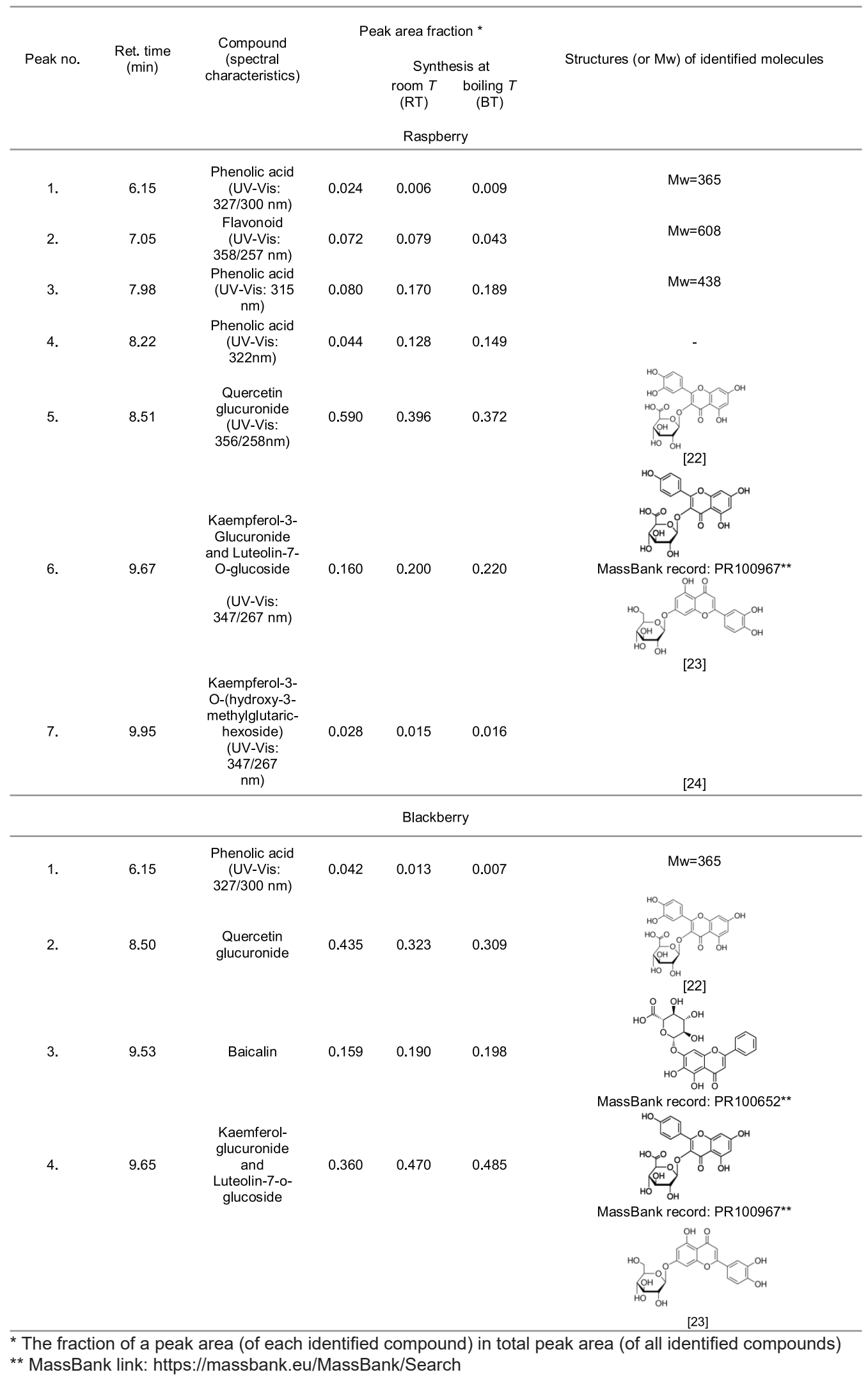


Based on chromatograms and peaks reduction, quercetin glucuronide is more incorporated in AgNPs$\mathrm{R}$ compared to kaempferol-3-glucuronide. In order to quantify this prediction, the fractions ratios for the peaks no.5\&6 were calculated as 3.69 (extract), 1.98 (RT) and $1.69(\mathrm{BT})$. A significant reduction of this ratio is strong evidence that quercetin glucuronide is engaged in capping, $\mathrm{Ag}+$ reduction and AgNPs stabilization to much higher extent compared to kaempferol-3-glucuronide. A similar analysis can be applied on other peaks i.e. compounds. The peak no.7 was identified as kaempferol3-O-(hydroxy-3-methylglutaric-hexoside); an analogous comparison to kaempferol-3-glucuronide (no.6) gave the ratios 5.71 (extract), 13.34 (RT) and 13.75 (BT) suggesting that kaempferol-3-O-(hydroxy-3-methylglutarichexoside) was incorporated in synthesized AgNPs-R to a significantly higher extent than kaempferol-3-glucuronide. It seems that the extra hydroxyl functional group favors the molecule for $\mathrm{Ag}^{+}$reduction and formed the nanoparticles stabilization. It can also be noticed that compounds no.1\&2 (Fig.7) were also significantly engaged in the nanoparticles formation. Compounds numbered 1 and 4 were identified as phenolic acids and their fraction ratios 1.84 (extract), 21.33 (RT) and 16.55 (BT) indicate a significant difference in the ability to $\mathrm{Ag}^{+}$ions reduction and AgNPs-R stabilization.

Some chosen compounds identified from the chromatograms of the blackberry extract and AgNPs-B supernatants (Fig.8) are listed in Table 1. The peaks fractions are changed in supernatants during AgNPs-B synthesis at room and boiling temperature compared to the extract. The most intensive peaks no.2\&4 are identified as quercetin glucuronide and a mixture of kaempferol-glucuronide and luteolin-7-o-glucoside, respectively. The fraction ratios of these peaks in the extract and supernatants were calculated as 1.21 (extract), 0.69 (RT) and 0.64 (BT), suggesting a higher activity of quercetin glucuronide compared to the mixture. The intensity of other peaks was decreased in supernatants, especially after the synthesis at boiling $T$. The phenolic acid under peak no.1 (Fig.8) is highly incorporated during the synthesis at both temperatures that is additionally illustrated through the relative comparison to no.2 peak giving the fraction ratio 10.35 (extract), 24.85 (RT) and 44.14 (BT). It should be emphasized that a particularly obvious reduction of some peaks intensity in the supernatants after AgNPs-E synthesis at boiling $T$ (Fig.7\&8) could be a consequence of their thermal degradation. Such possibility is avoided for the AgNPs-E synthesized at room $T$ where the differences in peak fraction ratios are still present. So, the compounds from the obtained extracts are certainly involved in AgNPs-E capping and stabilization via $\mathrm{Ag}^{+}$ions reduction. It is also unambiguous that present compounds have shown different reactivity depending on their structures. Some additional functional groups in the structure such as a hydroxyl group seem to favor the molecule for this type of reaction. Having this in mind, the results obtained with such a designed experiment should be a good starting point in further structure-activity relationship investigations and experimental setup improving.

\section{Antioxidant activity}

A comparative review of DPPH radical neutralization by extracts (obtained by maceration and reflux extraction, used in AgNPs-E synthesis), as well as by AgNPs$B$ and AgNPs-R (synthesized at room and boiling temperature) are shown in Fig.9. and Fig.10, respectively. The $\mathrm{EC}_{50}$ values, i.e. the concentrations of the extracts or AgNPs-E required for $50 \%$ of the initial DPPH radical neutralization are determined from the presented curves and given in Table 2 .

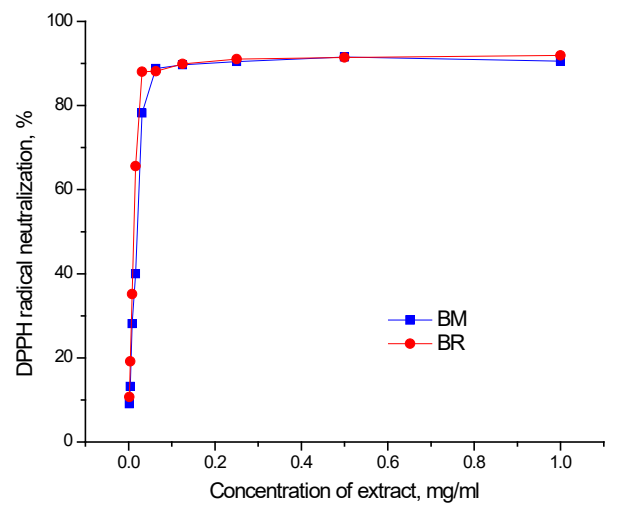

a)

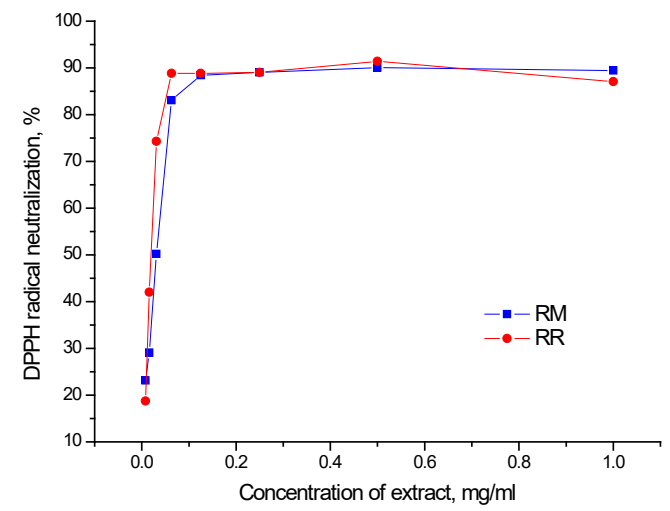

b)

Figure 9. DPPH radical neutralization (\%) as a function of the concentration of the extracts $(\mathrm{mg} / \mathrm{ml})$ obtained by maceration and reflux extraction from: blackberry leaves (a) and raspberry leaves (b). 


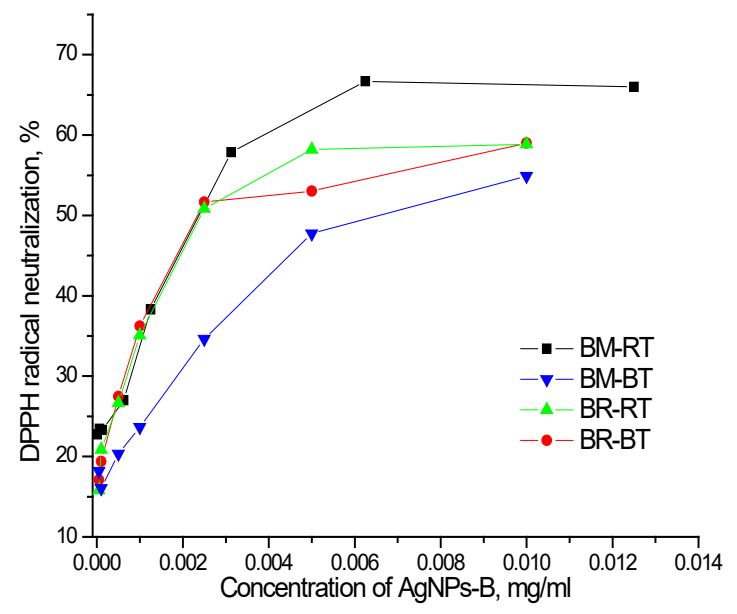

a)

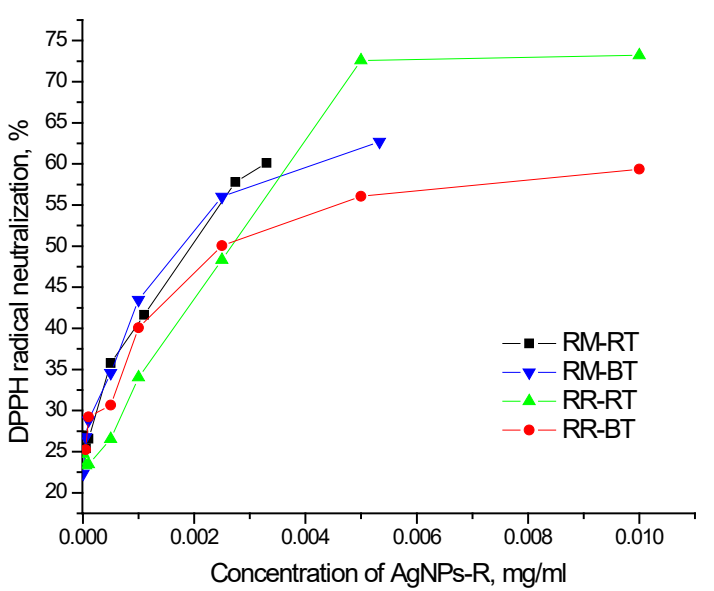

b)

Figure 10. DPPH radical neutralization (\%) as a function of AgNPs-E concentration (mg/ml) synthesized at room (RT) and boiling temperature (BT) from: blackberry extracts obtained by maceration (BM) and reflux extraction (BR) (a) and raspberry extracts obtained by maceration (RM) and reflux extraction (RR) (b).

Table 2. The $\mathrm{EC}_{50}$ values of raspberry and blackberry extracts (obtained by maceration and reflux extraction) and AgNPS-E (synthesized at room and boiling temperature) determined by DPPH test.

\begin{tabular}{|c|c|c|c|c|c|c|}
\hline & \multicolumn{6}{|c|}{$\mathrm{EC}_{50}$ values $[\mathrm{mg} / \mathrm{ml}]$} \\
\hline & \multirow{2}{*}{\multicolumn{2}{|c|}{ Extract }} & \multicolumn{4}{|c|}{ AgNPs-E } \\
\hline & & & \multicolumn{4}{|c|}{ Extract obtained by: } \\
\hline & \multirow{3}{*}{ Maceration } & \multirow{3}{*}{ Reflux } & $\mathrm{Ma}$ & tion & & \\
\hline & & & \multicolumn{4}{|c|}{ Synthesis at: } \\
\hline & & & Room $T$ & Boiling $T$ & Room $T$ & Boiling $T$ \\
\hline Raspberry (R) & 0.029 & 0.018 & 0.0019 & 0.0018 & 0.0038 & 0.0031 \\
\hline Blackberry (B) & 0.020 & 0.011 & 0.0024 & 0.0066 & 0.0024 & 0.0023 \\
\hline
\end{tabular}

The $\mathrm{EC}_{50}$ values of all investigated samples are given in Table 2. The AgNPs-R synthesized at the boiling temperature from the extract obtained by maceration at room $T$ have shown the highest antioxidant activity. It can be noticed that the extracts obtained by reflux extraction showed a higher activity compared to the extracts obtained by maceration suggesting a more effective extraction of active compounds by reflux extraction. It can also be noticed that the blackberry extract had a higher antioxidant activity than the raspberry extract, while the extract obtained by reflux extraction showed the highest antioxidant activity $\left(\mathrm{EC}_{50}=0.011\right)$. However, all the investigated extracts obtained by different extraction techniques have shown a similar antioxidant activity which was already noticed for other plant extracts [7, 25, 26].

Considering the antioxidant activity of AgNPs-E it can be noticed that synthesized nanoparticles have shown approximately ten times higher antioxidant activity than pure extracts (Table 2). On the other side, AgNPs-E synthesized at boiling $T$ from the raspberry extract obtained by maceration have shown the highest antioxidant activity with $\mathrm{EC}_{50}=0.018$. AgNPs-R synthesized from the extract obtained by maceration have shown a higher antioxidant activity than AgNPs-B while, at the same time, AgNPs-B synthesized from the extract obtained by reflux extraction have shown a higher antioxidant activity than analogous AgNPs-R (Table 2). Such inconsistent and opposite results encouraged us to continue further investigation using both plants, as well as both extraction and synthesis techniques.

The AgNPs-E synthesized by the above-described procedure have shown a higher ability to DPPH radical inhibition compared to earlier published results for AgNPs-tinctoria [27]. In addition, the nanoparticles synthesized from blackberry and raspberry extracts have also shown lower $\mathrm{EC}_{50}$ values than AgNPs obtained from the aqueous extract of Iresine herbstii leaf [28], Ganoderma applanatum [29] and Artemisia vulgaris leaves [30]. Taking into account the indicated antioxidant activity, further usage of silver nanoparticles synthesized by methods described above should be certainly taken into consideration in a cosmetic preparations design.

\section{Conclusion}

Synthesized silver nanoparticles, stabilized by biomolecules from aqueous extracts of blackberry and raspberry leaves have been structurally characterized by UV-Vis and FTIR spectroscopy. The size of synthesized nanoparticles was determined by SPR band position in the range of $17-61 \mathrm{~nm}$. The nanoparticles have shown high stability at room temperature in the dark, monitored by UV-Vis spectroscopy. The phenolic acids and flavonoids derivatives were mostly identified in the extracts 
by LC-MS analysis. According to the comparative LCMS analysis of the extracts and supernatants (of centrifuged nanoparticles suspensions), it was concluded that some compounds are involved to a higher extent in $\mathrm{Ag}+$ ions reduction and formed nanoparticles stabilization, depending on their structural characteristic. Finally, the silver nanoparticles synthesized by described green methods have shown a comparatively high antioxidant activity estimated by DPPH test, deserving to be taken into account as a base in further cosmetic preparations design.

\section{Acknowledgments}

This research is a part of Projects TR-34012 supported by the Ministry of Education, Science and Technological Development of the Republic of Serbia.

\section{Abbreviations and symbols}

AgNPs - silver nanoparticles

AgNPs-E - silver nanoparticles synthesized using plant extracts

AgNPs-B - silver nanoparticles synthesized using blackberry extracts

AgNPs-R - silver nanoparticles synthesized using raspberry extracts

$\mathrm{RT}$ - room temperature

BT - boiling temperature

$M$ - Maceration

$R$ - Reflux extraction

BM-RT - Blackberry, extract obtained by Maceration nanoparticles synthesized at Room Temperature

BM-BT - Blackberry, extract obtained by Maceration nanoparticles synthesized at Boiling Temperature BR-RT - Blackberry, extract obtained by Reflux extraction - nanoparticles synthesized at Room Temperature BR-BT - Blackberry, extract obtained by Reflux extraction - nanoparticles synthesized at Boiling Temperature RM-RT - Raspberry, extract obtained by Maceration nanoparticles synthesized at Room Temperature

RM-BT - Raspberry, extract obtained by Maceration nanoparticles synthesized at Boiling Temperature RR-RT - Raspberry, extract obtained by Reflux extraction - nanoparticles synthesized at Room Temperature RR-BT - Raspberry, extract obtained by Reflux extraction - nanoparticles synthesized at Boiling Temperature

\section{References}

[1] K.W. Guo, Nanomaterials formed by green nanotechnology for bioapplication, Nova Science Publishers, Inc., (2014) 241-310.

[2] M. Cakić, S. Glišić, D. Cvetković, M. Cvetinov, Lj. Stanojević, B. Danilović, K. Cakić, Green synthesis, characterization and antimicrobial activity of silver nanoparticles produced from Fumaria officinalis L. plant extract, Colloid Journal, 80(6) (2018) 803-813.

[3] J.L.P. Reátegui, A.P.F. Machado, G.F. Barbero, C.A. Rezende, J. Martínez, Extraction of antioxidant compounds from blackberry (Rubus $s p$.) bagasse using supercritical $\mathrm{CO}_{2}$ assisted by ultrasound, The Journal of Supercritical Fluids, 94 (2014) 223-233.

[4] E. Gutierrez, A.G. Villaraco, J.A. Lucas, A. Gradullas, F.J.G. Mañero, B.R. Solano, Transcriptomics, targeted metabolomics and gene expression of blackberry leaves and fruits indicate flavonoid metabolic flux from leaf to red fruit, Frontiers in Plant Science, 8 (2017) 1-15.

[5] E. Aprea, S. Carlin, L. Giongo, M. Grisenti, F. Gasperi, Characterization of 14 raspberry cultivars by solidphase microextraction and relationship with gray mold susceptibility, Journal of Agricultural and Food Chemistry, 58 (2010) 1100-1105.

[6] D. Cvetković, D. Marković, UV-effects on antioxidant activity of selected carotenoids in the presence of lecithin estimated by DPPH test, Journal of the Serbian Chemical Society, 73(11) (2008) 1051 - 1061

[7] Lj. P. Stanojević, A.S. Zdravković, M.Z. Stanković, M.D. Cakić, V.D. Nikolić, D.P. Ilić, Antioksidativna aktivnost vodeno-etanolnih ekstrakata iz lista koprive (Urtica dioica L.), Savremene tehnologije (In Serbian), 2(1) (2013) 51 59 .

[8] N. Bednar, Synthesis of metallic nanoparticles in electrolyte-plasma interface. Thesis, Faculty of Technical Sciences, University of Novi Sad, Serbia, 2014.

[9] D. Mubarak Ali, N. Thajuddin, K. Jeganathan, M. Gunasekaran, Plant extract mediated synthesis of silver and gold nanoparticles and its antibacterial activity against clinically isolated pathogens, Colloids and Surfaces B: Biointerfaces, 85.2 (2011) 360 - 365.

[10] J. Huang, Q. Li, D. Sun, Y. Su, X. Yang, H. Wang, Y. Wang, W. Shao, N. He, J. Hong, C. Chen, Biosynthesis of silver and gold nanoparticles by novel sundried Cinnamomum camphora leaf, Nanotechnology, 18 (2007) 1 - 12.

[11] R. Amooaghaie, M. R. Saeri, and M. Azizi, Synthesis, characterization and biocompatibility of silver nanoparticles synthesized from Nigella sativa leaf extract in comparison with chemical silver nanoparticles, Ecotoxicology and Environmental Safety, 120 (2015) 400 - 408.

[12] O. Velgosova, A. Mražíková, E. Čižmárová, J. Málek, Green synthesis of $\mathrm{Ag}$ nanoparticles: Effect of algae life cycle on Ag nanoparticle production and long-term stability, Transactions of Nonferrous Metals Society of China, 28 (2018) 974-979.

[13] C.S. Espenti, K.S.V.K. Rao, K.M. Rao, Bio-synthesis and characterization of silver nanoparticles using Terminalia chebula leaf extract and evaluation of its antimicrobial potential, Material Letters, 174 (2016) 129-133.

[14] M. A. Garcia. Surface plasmons in metallic nanoparticles: fundamentals and applications. Journal of Physics D: Applied Physics, IOP Publishing, 44 (28) (2011) pp.283001. 10.1088/0022-3727/44/28/283001

[15] A. Ebrahiminezhad, Y. Ghasemi, S. Rasoul-Amini, J. Barar, S. Davaran, Impact of amino-acid coating on the synthesis and characteristics of iron-oxide nanoparticles (IONs), Bulletin of the Korean Chemical Society, 33 (2012) 3957.

[16] V.V. Kumar, S.C. Yadov, S.K. Yadov, Syzygium cumini leaf and seed extract mediated biosynthesis of silver nanoparticles and their characterization, Journal of 
Chemical Technology \& Biotechnology, 85 (2010), p. 1301.

[17] M. Sathishkumar, K. Sneha, S.W. Won, C.-W. Cho, S. Kim, Y.-S. Yun, Cinnamon zeylanicum bark extract and powder mediated green synthesis of nano-crystalline silver particles and its bactericidal activity, Colloids and Surfaces B: Biointerfaces 73.2 (2009) 332 - 338.

[18] H. Bar, D.K. Bhui, G.P. Sahoo, P. Sarkar, S.P. De, A. Misra, Green synthesis of silver nanoparticles using latex of Jatropha curcas, Colloids and surfaces A: Physicochemical and engineering aspects, 339.1 (2009) $134-139$.

[19] S. Glišić, M. Cakić, G. Nikolić, B. Danilović, Synthesis, characterization and antimicrobial activity of carboxymethyl dextrane stabilized silver nanoparticles, Journal of Molecular Structure (2015) 345-351.

[20] M.Cakić, S. Glišić, G. Nikolić, G.M. Nikolić, K. Cakić, M. J. Cvetinov, Synthesis, characterization and antimicrobial activity of dextran sulphate stabilized silver nanoparticles, Journal of Molecular Structure (2016) 156-161.

[21] G. Nikolić, M. Cakić, S. Glišić, D. Cvetković, Ž. Mitić, D. Marković, In Fourier Transforms. High-tech Application and Current Trends, G. Nikolić, M. Cakić, D. Cvetković Eds., InTech, Rijeka, Croatia 2016, p. 149.

[22] M. Dueñas, H. Mingo-Chornet, J. J. Pérez-Alonso, R. Di Paola-Naranjo, A. M. González-Paramás, C. SantosBuelga, Preparation of quercetin glucuronides and characterization by HPLC-DAD-ESI/MS, European Food Research and Technology, 227 (2008) 1069-1076.

[23] Z-H. Li, H. Guo, W-B. Xu, J. Ge, X. Li, M. Alimu, .D-J. $\mathrm{He}$, Rapid identification of flavonoid constituents directly from PTP1B inhibitive extract of raspberry (Rubus idaeus L.) leaves by HPLC-ESI-QTOF-MS-MS, Journal of Chromatographic Science, 54(5) (2016) 805-810.

[24] V. Spínola, J. Pinto, P.C. Castilho, Identification and quantification of phenolic compounds of selected fruits from Madeira Island by HPLC-DAD-ESI-MSn and screening for their antioxidant activity, Food Chemistry 173 (2015) 14-30.

[25] Dragan J. Cvetković, Ljiljana P. Stanojević, Mihajlo Z. Stanković, Milorad D. Cakić, Saša R. Savić \& Marko D. Miljković, Antioxidant activity of strawberry (Fragaria $\times$ ananassa Duch.) leaves, Separation Science and Technology, 52 (6) (2017) 1039-1051.

[26] Ljiljana P. Stanojević, Mihajlo Z. Stanković, Amer Juma, Antioxidant activity of aqueous extracts from dill fruit (Anethi fructus) obtained by different extraction techniques, Advanced technologies, 5(2) (2016) 46-52.

[27] R. Vijayan, S. Joseph, B. Mathew, Indigofera tinctoria leaf extract mediated green synthesis of silver and gold nanoparticles and assessment of their anticancer, antimicrobial, antioxidant and catalytic properties, Artificial cells, nanomedicine, and biotechnology, 46 (2018) 861871.

[28] C. Dipankar, S. Murugan, The green synthesis, characterization and evaluation of the biological activities of silver nanoparticles synthesized from Iresine herbstii leaf aqueous extracts, Colloids and Surfaces B: Biointerfaces, 98 (2012) 112- 119.

[29] S. Jogaiah, M. Kurjogi, M. Abdelrahman, N. Hanumanthappa, L.S.P. Tran, Ganoderma applanatummediated green synthesis of silver nanoparticles: Structural characterization, and in vitro and in vivo biomedical and agrochemical properties, Arabian Journal of Chemistry, (2018) 1-13.
[30] T. Rasheed, M. Bilal, H.M.N. Iqbal, C. Li, Green biosynthesis of silver nanoparticles using leaves extract of Artemisia vulgaris and their potential biomedical applications, Colloids and Surfaces B: Biointerfaces, 158 (2017) 408-415. 
Izvod

\section{SINTEZA, KARAKTERIZACIJA I ANTIOKSIDATIVNA AKTIVNOST NANOČETICA SREBRA STABILIZOVANIH VODENIM EKSTRAKTIMA LISTA DIVLJE KUPINE (Rubus spp.) I MALINE (Rubus idaeus L.)}

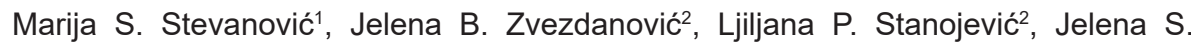
Stanojević ${ }^{2}$ Sanja M. Petrović ${ }^{2}$, Milorad D. Cakić ${ }^{2}$, Dragan J. Cvetković ${ }^{2}$

${ }^{1}$ Stipendista Ministarstva prosvete, nauke i tehnološkog razvoja Republike Srbije, Tehnološkog fakulteta u Leskovcu, Univerziteta u Nišu, Leskovac, Srbija

2Univerzitet u Nišu, Tehnološki fakultet u Leskovcu, Leskovac, Srbija

$U$ radu su opisane zelene metode sinteze nanočestica srebra (AgNPs-E) i njihova stabilizacija biomolekulima iz vodenih ekstrakata listova divlje kupine (Rubus spp.) i maline (Rubus idaeus L.). Ekstrakti, dobijeni iz obe biljke maceracijom i refluks ekstrakcijom, korišćeni su u sintezi nanočestica na dve različite temperature (sobnoj i temperaturi ključanja). Strukturna karakterizacija sintetisanih AgNPs-E izvedena je UV-Vis i FTIR spektroskopijom. Veličina i visoka stabilnost sintetisanih nanočestica, na sobnoj temperaturi u mraku, predviđene su i dokazane praćenjem SPR trake u UV-Vis spektrima. Hemijski sastav čistih ekstrakata i supernatanata, dobijenih centrifugiranjem AgNPs-E suspenzija, određen je pomoću LC-MS analize. Većina identifikovanih jedinjenja pripada fenolnim kiselinama i derivatima flavonoida. Komparativna LC-MS analiza ekstrakta i supernatanata pokazala je da su neka jedinjenja iz ekstrakata uključena u većoj meri u redukciji Ag jona i stabilizaciji formiranih čestica, sugerišući da postoji zavisnost aktivnosti biomolekula od njihove strukture kad je u pitanju ovaj tip reakcija. Sintetisane AgNPs-E su pokazale relativno visoku antioksidativnu aktivnost procenjenu DPPH testom zbog čega ih treba uzeti u obzir kao osnovu za dalje kreiranje preparata za zaštitu kože.
(ORIGINALNI NAUČNI RAD)

UDK 582.712:66.063.4:546.57

Ključne reči: kupina, malina, vodeni ekstrakt, nanočestice srebra, antioksidativna aktivnost 